\title{
Improvement and Properties of Fiber Metal Laminates Used in Aircraft Wing by Using Graphite-Polyester
}

\author{
Ahmed M. Kadhum, Saad T. Faris, Ali A. Al-katawy \\ Department of Mechanical Engineering, College of Engineering, University of Daiyla
}

\begin{abstract}
The main objective of this study is to reduce weight and to improve the mechanical properties of aircraft wing by using Hybrid materials known as fiber metal laminates (FMLs). They are new age of engineering materials, which consist of metal layers reinforced with fibers emerged by matrix phase. In this study, seven layers were used to produce the FMLs, which are consist of aluminum alloy2024-T3 reinforced by carbon and glass fibers bonded with using blend of graphite-polyester as adhesion. The Carbon Glass Reinforced Aluminum Laminates (CAGRALLs) is used as FMLs. The results show that the CAGRALLs give better in mechanical properties because of increasing in tensile strength, yield strength, elastic modulus, elongation at fracture, flexural modulus and impact toughness except flexural strength by comparing with FMLs by using commercial epoxy as adhesion for other researchers. The increasing in layers is led to weaken adhesion force between layers of FMLs that led to decrease almost mechanical properties. The FMLs has good mechanial properties by using carbon and glass fiber by comparing with carbon and jute fibers. The CAGRALLs have the higher numbers of cycles at failure under cyclic loadings than Aramid Reinforced Aluminum Laminates (ARALLs). The CAGRALLs have the lower density by comparing with aluminum alloy 2024-T3 and steel that used in manufacturing of aircraft wing.
\end{abstract}

Keywords: Fiber metal laminates; Mechanical properties; Hybrid composite materials..

Paper History: (Received:10-9-2018 ; Accepted:27-122018)

\section{Introduction}

Advanced composite materials may increase using in the civil aircraft primary structures. They used in control surfaces, wings, aero-engines, fan castings, etc. When the civil aircraft is subjected to high velocity impacts, these materials are all safety critical components [1]. Hybrid materials are composite materials which mixing two or more different fibers within layer by layer. They have designed based on beneficial of different properties of the fibers employed. For example, the mixing of glass fiber with carbon fiber has embedded within a polymer matrix gives inexpensive composite because the glass fiber has been the low cost but with mechanical properties enhanced by the excellent stiffness of carbon [2]. Fiber metal laminates (FMLs) is the new light weight materials which can be fabricated by merge the formability of metals and advanced characteristics of composite materials to form one material system (see figure 1). They can be created by bonding of composite laminates plies with metal sheet. They have high strength and stiffness to weight ratio, high corrosion resistance and excellent fatigue characteristics. The lay up process is away for using to make FMLs parts based on thermosetting polymers. They have the potential for superior formability characteristics of monolithic aluminum like less shape error, lower strain and delamination [3]. During year 1978, Aramid Reinforcement Aluminum Laminate (ARALL) has the first fiber metal laminate development by Aerospace department of Delft University of technology Netherlands and it made commercially available in 1982 [4]. In 1987s, the new FMLs have patented where the glass fibers have used instead of aramid fibers because glass fiber (GLARE) has superior impact behavior. In 1990s, the GLARE has applied on the floor structures of the Boeing 777. In 1997s, the GLARE was used as skin material of Airbus A380-800 in Approx. $470 \mathrm{~m}^{2}$. Now, the GLARE is the FMLs standard, which can be used as the material for Airbus Aircraft. This GLARE made of aluminum sheets 2024T3 and S2-glass fiber unidirectional prepreg with epoxy adhesive cured at $120^{\circ} \mathrm{C}$ [5]. The graphite and carbon fiber are interchangeably used within the composite materials. The elemental carbon content of graphite and carbon fiber is above $90 \%$. The fiber has stiff and strong when the elemental carbon content approaching $100 \%$. The graphite fiber has the elemental carbon content is being above $95 \%$, the heat treatment at temperature is exceeding $1700^{\circ} \mathrm{C}$, high degree of preferred crystalline orientation when it is stretched during heat treatment and the modulus of elasticity on the order of $345 \mathrm{GPa}$. Fibers are not satisfied all of the above conditions known as carbon fibers. The graphite and carbon fibers are basically produced by decomposition of an organic ( i.e. ,polymeric) fiber or precursor at high temperatures and pressures [6]. It is the type of polymers with ester functional group on the main chain. There are many types of polyester. The term "polyester" can be referred to poly (ethylene terephthalate) (PET) and poly (butylenes terephthalate) (PBT) in industries specially. It can be classified into two divisions: as thermosetting or thermoplastic depending on the chemical structure [7]. Unsaturated polyester is the important resin for glass fiber reinforced composites. To obtain on it, there two step process; firstly, reaction of unsaturated and saturated acids or abhydrides with diols in poly condensation reaction, secondly the resulting linear polyester prepolymeris dissolve dinstyrene into syrup like resin. The finally resin has processed into a rigid thermoset in co-polymerisation between styrene and double bonds in the polyester chain. The unsaturated polyester holds the reinforcement in composites. It is transferred external load 
to the reinforcement and protects the reinforcement from the environment. The matrix-redistributed load to surrounding fibers when the fibers are fractured that have preventing the complete failure of the material. Unsaturated polyester have used in marine, automotive, electric, electronic, building, construction and military applications [8]. Unsaturated polyester is the most commonly used as matrix for fiber-reinforced plastics. The thermoset polyester has used in many applications like automotive, aircraft, electrical and appliance components instead of traditional materials. The advantages of it are low cost, good electrical insulation, very good mechanical properties, good chemical resistance and low density [9].. Aluminum alloy 2024-T3 has high strength to weight ratio as well as good fatigue resistance [10]. It has used for high strength structural applications. It has the excellent machinability in the T-tempers.it has fair workability and corrosion resistance. It used for aircraft structures applications, gears for machinery, screw machine product, machine parts, automotive parts, cylinder and pistons, fasteners screw and rivets [11]. The transition fatigue life was found experimentally to be about 20100 cycles for alloy AA2024T6 [12]. The cutout of the skin of the wing through its thickness caused a small decreasing in the natural frequencies. The increasing in the cutout ratio and the number of damaged panels caused a small decrease in the natural frequencies. The variation in the location of the cutout along the wing span and the wing width caused very small effect on the natural frequencies [13].Chlupová,et al studied the fatigue crack growth of the Glass Reinforced
Aluminum Laminates (GLARE) [14]. Vasumathi et al studied the mechanical properties of Carbon Jute Reinforced Aluminum Laminates (CAJRALL) and Carbon Jute Reinforced Magnesium Laminates (CAJRMAL). The tensile strength was increased with increased number of layers and the decreased with increasing number of layers. The young's modulus, flexural strength, flexural modulus and impact toughness were decreased with increasing number of layers. [15]. Qaiser et al., studied the mechanical properties of Aramid Reinforced Aluminum Laminates (ARALL) [16]. Rajkumar et al studied the tensile and flexural of FMLs. The Aluminum and Carbon Fiber Reinforced Plastics had better bonding that lead to arrest the crack in the flexural test. The Aluminum and Glass Fiber Reinforced Plastics had greater tendency for debonding between fiber and the resin matrix [17]. Hassan et al studied the tensile and flexural of GLARE. The numbers of layers were 1, 2, 4, 6 and 8 layers were used in fabricating the GLARE. The numbers of layers in GLARE were increased that lead to give good strength. The delamination of GLARE was weak with increasing the number of layers in GLARE [18]. Harichandan et al., studied the tensile behavior of Carbon Jute Aluminum Laminates (CAJALL) [19].

In the present study, the mechanical properties (tensile, flexural, impact and fatigue) of CAGRALLs have studied that used in aircraft wings. The CAGRALLs made of aluminum sheets reinforced by carbon and glass fibers have bonded by using grahiye-polyester

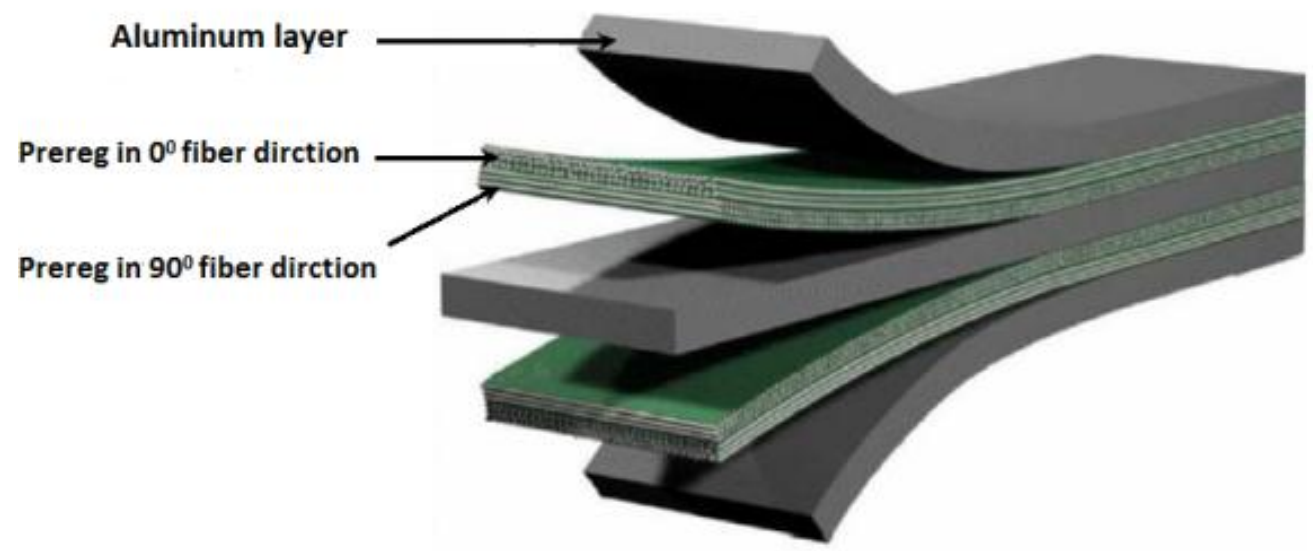

Figure 1. Schematic presentation of FMLs [20]

\section{Exprimental Work \\ Hand lay-up}

The Hand lay- up technique has used in this study since it is low cost tool and light load applications. It is more used in fabriation of FMLs. It is the simplest and oldest open molding method of the composite fabrication processes. It is a low volume, labor intensive method suited especially for large components, such as boat hulls. Glass or other reinforcing mat or woven fabric or roving is positioned manually in the open mold, and resin is poured, brushed, or sprayed over and into the glass plies. Entrapped air is removed manually with squeegees or rollers to complete the laminates structure. Room temperature curingpolyesters and epoxies are the most commonly used matrix resins. Curing is initiated by a catalyst in the resin system, which hardens the fiber reinforced resincomposite without external heat. For a high quality part surface, a pigmented gel coat is first applied to the mold surface. The preparation of the mould with tools has done after the preparation of raw materials. The reinforcement materials have used as fiber fabric or fillers well mix with some resins to give its bonding with aluminum sheet. The materials used like fibers and aluminum sheets are cut according to the desired size and held in the mould. The 
pressing by roller has applied to the skins. The applied pressure compresses the prepreg for improving the bonding between the fibers and aluminum sheets. The time must be enough for been suitable bonding (See figure 2).
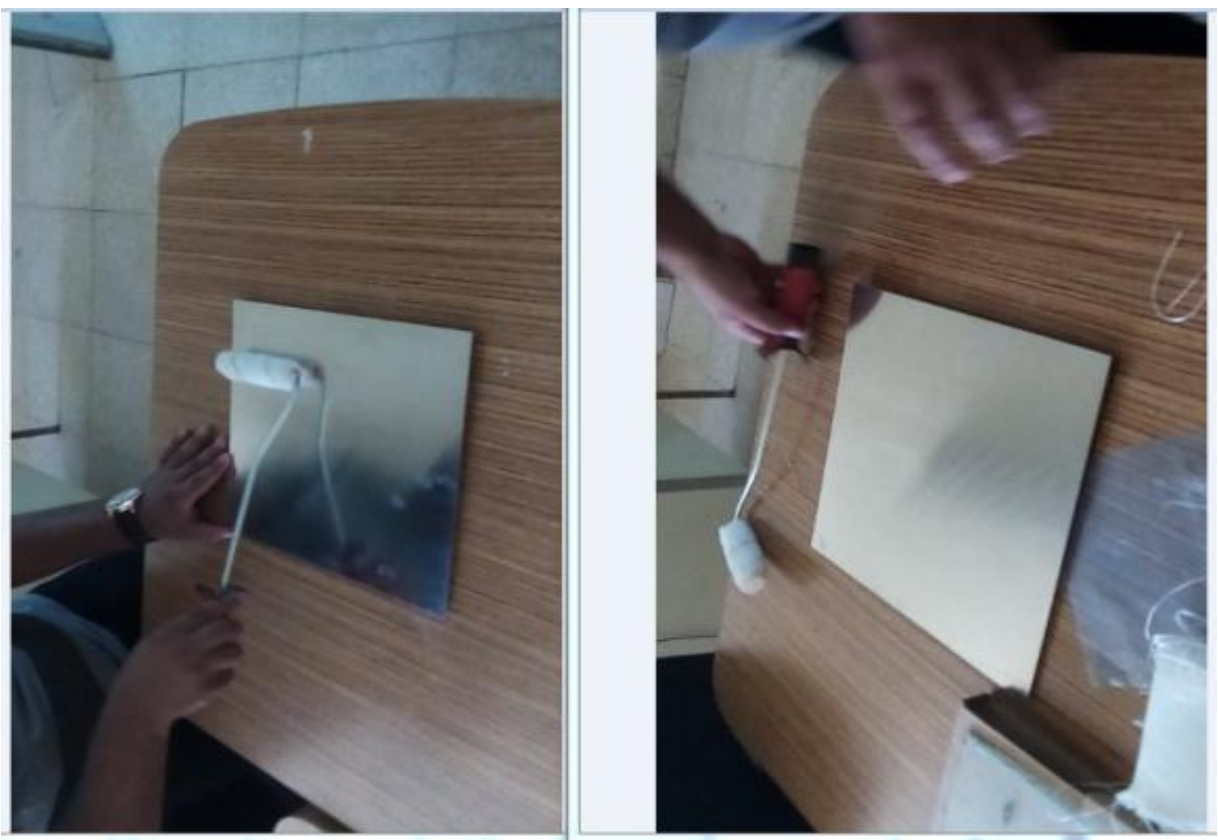

Figure 2. Hand lay-up technique

\section{Materials}

The materials have used for fabricating the FMLs, which are the polyester ES-1060 resin, graphite powder $\left(2.12 \mathrm{~g} / \mathrm{cm}^{3}\right)$, carbon fiber SikaWrap-301C, E-Glass fiber EWR450 and aluminum alloy sheet 2024-T3 (see table 1,2 and 3). Graphite powder is mixed with polyester with percent $8 \%$. Adding of graphite to polyester resin led to improve the mechanical properties and increase adhesion force between layers because polyester is a weak adheasion [21]. The oreintation of fibers is woven roving $\left(45^{\circ}\right)$ and uniderection $\left(0^{0}\right)$ to give the same stresses at all directions. The weight friction is 0.2 for fiber that has used in this work. The specimens 1 and specimen 2 have the same conditions that consist of seven layers (Al/C90/G45/Al/ G45/C90/Al) which used in this work. There is no need to study nultiple layers because of inreasing in layers caused dereasing the mechanical properties, inreasing in thichness and weak adhesion force between layers. The CNC water jet machine has used as the cutting machines, which has used for cutting the hard materials by water jetting (see figure 3 ). It gives accuracy dimension and donot cause demage for specimen. It has used for cuting specimens according to ASTM test standard.

[Table Properties of 1060-ES polyester [22

\begin{tabular}{|c|c|}
\hline Appearance & Clear liquid \\
\hline Viscosity & 4500 mpa.s \\
\hline Density & $1.15 \mathrm{~g} / \mathrm{cm}^{3}$ \\
\hline Shelf life & $6 \mathrm{months}$ \\
\hline Tensile strength & $65 \mathrm{MPa}$ \\
\hline $\begin{array}{c}\text { Modulus of } \\
\text { elasticity }\end{array}$ & $3 \mathrm{GPa}$ \\
\hline Elongation at break & $1.8 \%$ \\
\hline Flexural strength & 120 \\
\hline Pot life min & 5 \\
\hline
\end{tabular}

Table 1. Properties of fibers used in this study $[23,24]$

\begin{tabular}{|c|c|c|}
\hline Property & EWR 450 & SIikawrap301 C \\
\hline Material & E-glass fiber & Carbon fiber \\
\hline Color & white & black \\
\hline
\end{tabular}




\begin{tabular}{|c|c|c|}
\hline Orientation & $45^{\circ}$ (Woven Roving) & $0^{0}$ (unidirectional) \\
\hline Density & $1.5 \mathrm{~g} / \mathrm{cm}^{3}$ & $1.8 \mathrm{~g} / \mathrm{cm}^{3}$ \\
\hline Thickness & $0.3 \mathrm{~mm}$ & $0.167 \mathrm{~mm}$ \\
\hline Tensile strength & $2400 \mathrm{MPa}$ & $4900 \mathrm{MPa}$ \\
\hline Elongation at breake & $<2 \%$ & $1.9 \%$ \\
\hline
\end{tabular}

Table 2. Properties of aluminum alloy 2024-T3 [25]

\begin{tabular}{|c|r|}
\hline Property & Value \\
\hline Density & $2.78 \mathrm{~g} / \mathrm{cm}^{3}$ \\
\hline Tensile strength & $435 \mathrm{MPa}$ \\
\hline Yield strength & $290 \mathrm{MPa}$ \\
\hline Elongation & $10-15 \%$ \\
\hline Endurance limit & $138 \mathrm{Mpa}$ \\
\hline Elastic modulus & $73.1 \mathrm{GPa}$ \\
\hline Poisson's ratio & 0.33 \\
\hline
\end{tabular}

Table 3. Chemical composition of AL 2024-T3 [25]

\begin{tabular}{|c|c|}
\hline Component & Wt. \% \\
\hline $\mathrm{Cr}$ & 0.1 \\
\hline $\mathrm{Cu}$ & $3.8-4.9$ \\
\hline $\mathrm{Fe}$ & 0.5 \\
\hline $\mathrm{Mg}$ & $1.2-1.8$ \\
\hline $\mathrm{Mn}$ & $0.3-0.9$ \\
\hline $\mathrm{Si}$ & 0.5 \\
\hline $\mathrm{Ti}$ & 0.15 \\
\hline $\mathrm{Zn}$ & 0.25 \\
\hline Other each & 0.05 \\
\hline Other total & 0.15 \\
\hline $\mathrm{AL}$ & Reminder \\
\hline
\end{tabular}

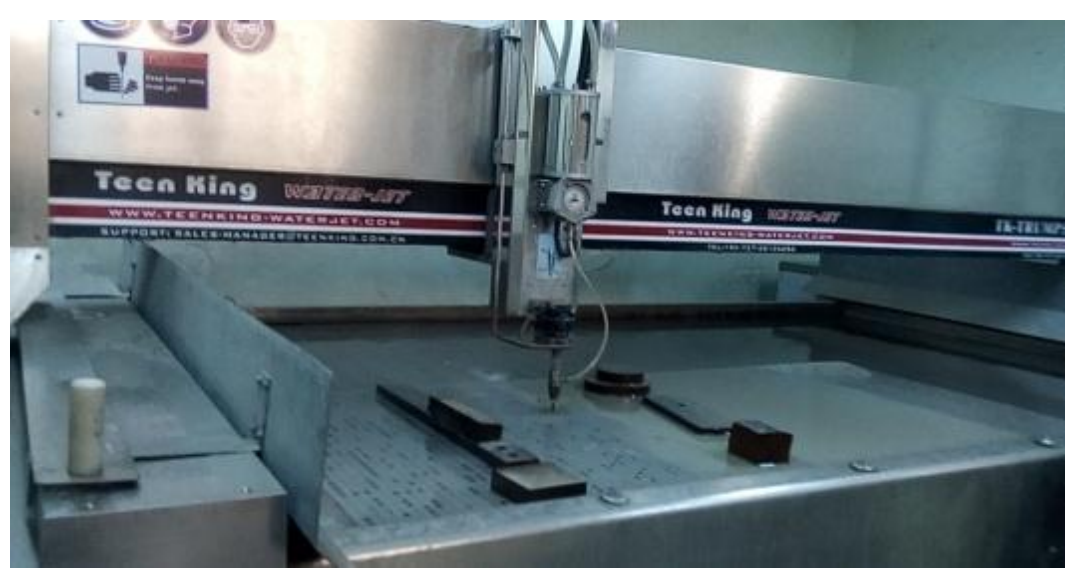

Figure 3. The CNC water jet machin

\section{Mechanical testing}

\section{Tensile test}

The tensile test is more used for determine the mechanical properties for all materials. This test has done according to the standard ASTM D-638 at room temperature in the University of Technology/ Materials Engineering/in the materials strengths lab. The shape of the tensile test specimens is as bone of a dog (see figure 4) and the samples during testing (see figure 5). 


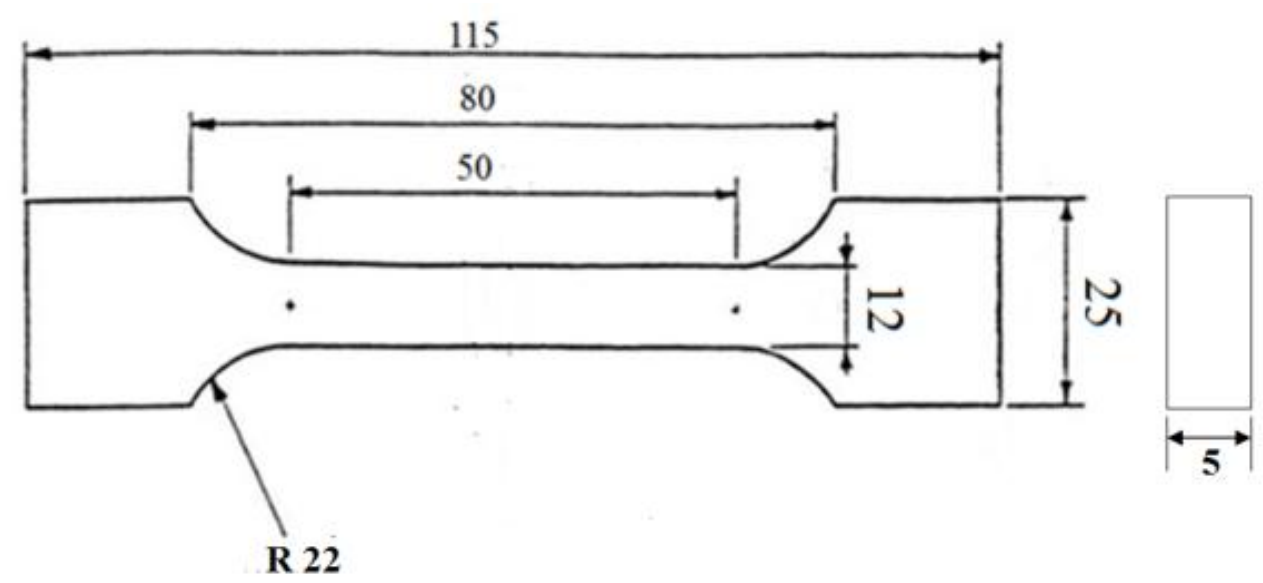

Note: All dimensions in $\mathrm{mm}$

Figure 4. Sample tensile test
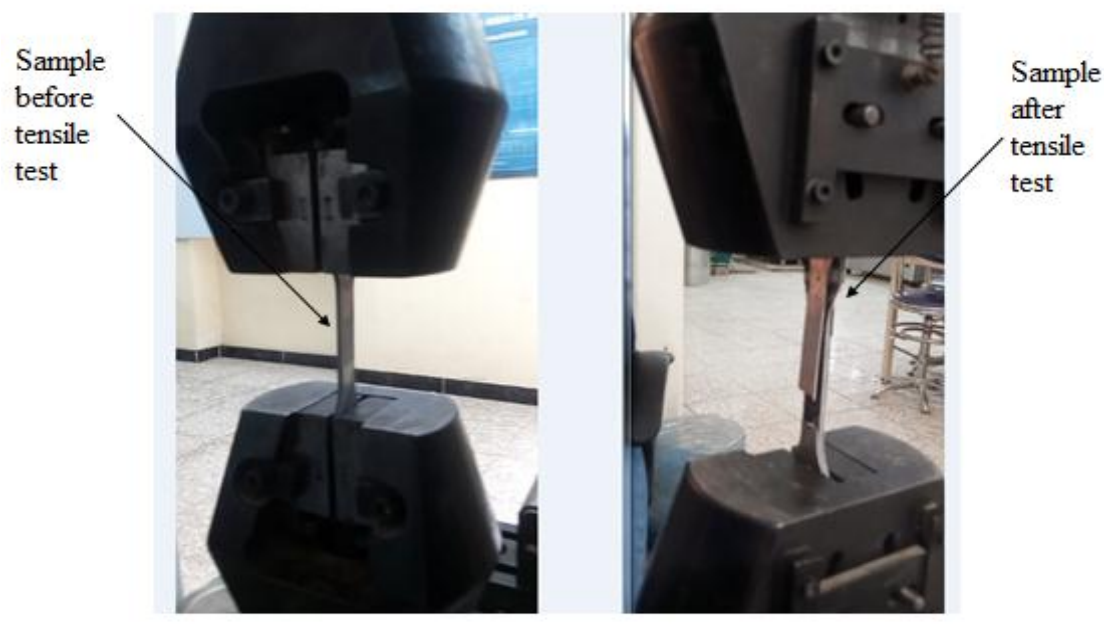

Figure 5. The tensile sample during test

\section{Flexural test}

The flexural test is important for the mechanical properties of materials. The flexural test is done according to the standard ASTM D790 at room temperature in the university of Technology /Applied Science Department / the strength of materials lab. The three points flexural has used in the research (see figure 6). The flexural specimen is the parallel rectangles shape with dimensions $(100 \times 10$ $\mathrm{x} 5 \mathrm{~mm}$ ) which shown in figure 7 . 


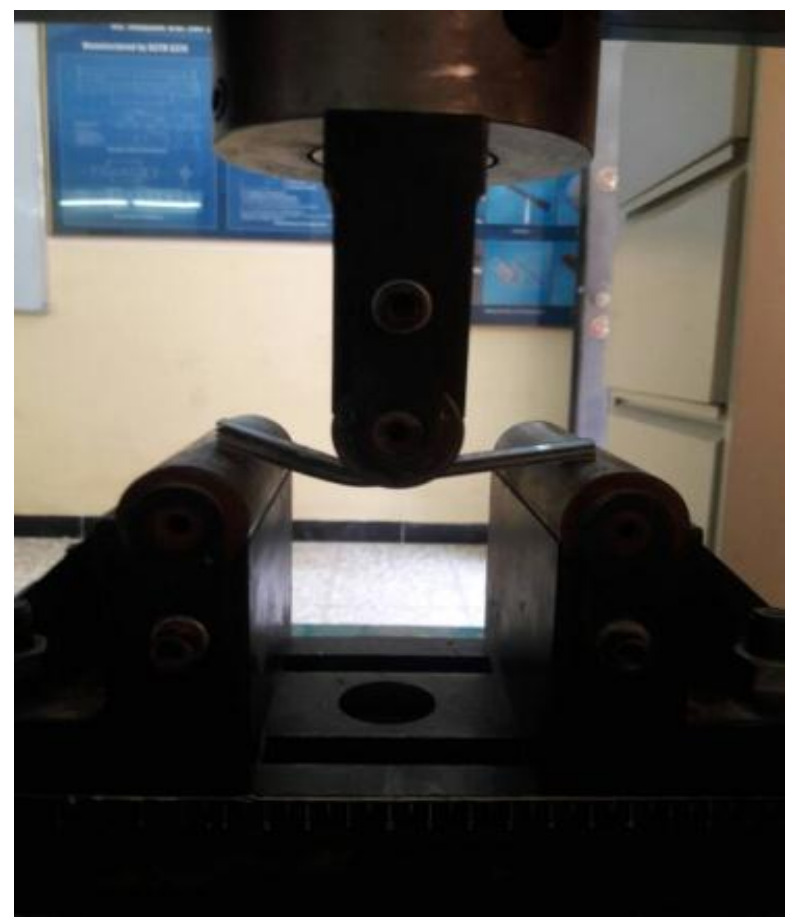

Figure 6. Flexural test apparatus

100

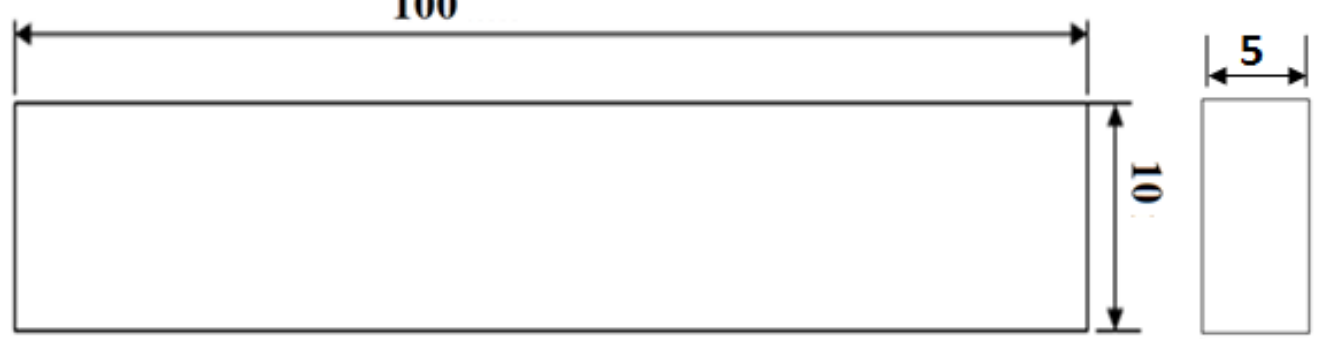

Figure 7. Flexural test specimen

Note: All dimensions in $\mathrm{mm}$

\section{Impact test}

The charpy impact test has used to determine the magnitude of impact force for materials that resist this load through the absorption of energy of these materials. It is done with using (300 Joule) pendulum impact test machine. The impact test has done according to the standard ISO 179 at room temperature in the General Company for Engineering Inspection and Rehabilitation. The impact test specimen is the parallel rectangles with dimensions: long: $55 \mathrm{~mm}$, wide: $10 \mathrm{~mm}$ and thickness 5 $\mathrm{mm}$, as shown in figure 8 .

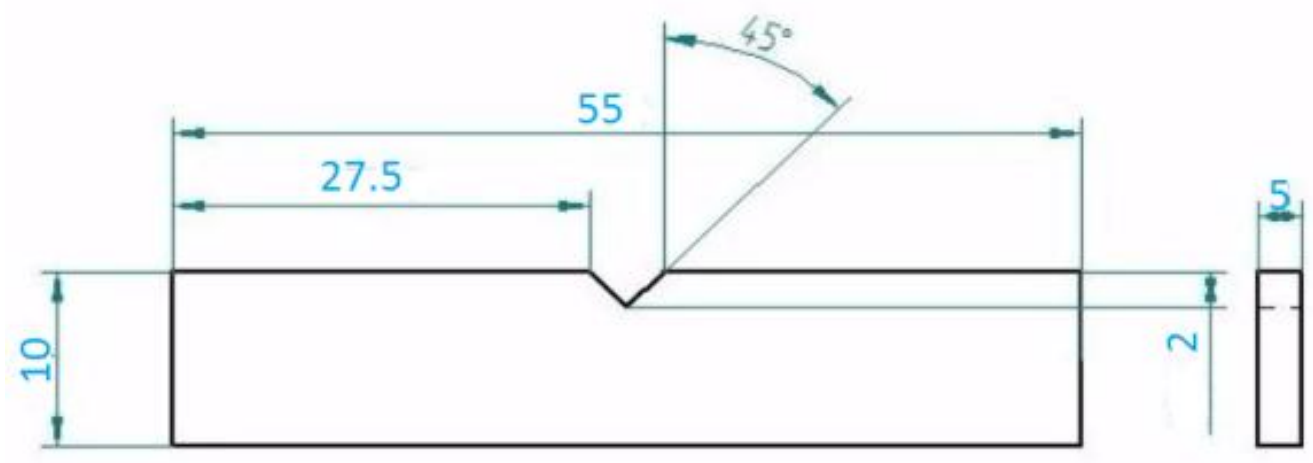

Figure 8. Impact test specimen 


\section{Fatigue test}

The fatigue test is very important for mechanical applications. It has studied fatigue failure of materials. It has done by using a rotating cantilever load at the end. It has done according to standard HSM 19 Rotating fatigue Machine. The fatigue test specimen is the parallel rectangles with dimensions $(100 \times 10 \times 5 \mathrm{~mm})$ which shows in figure 9.

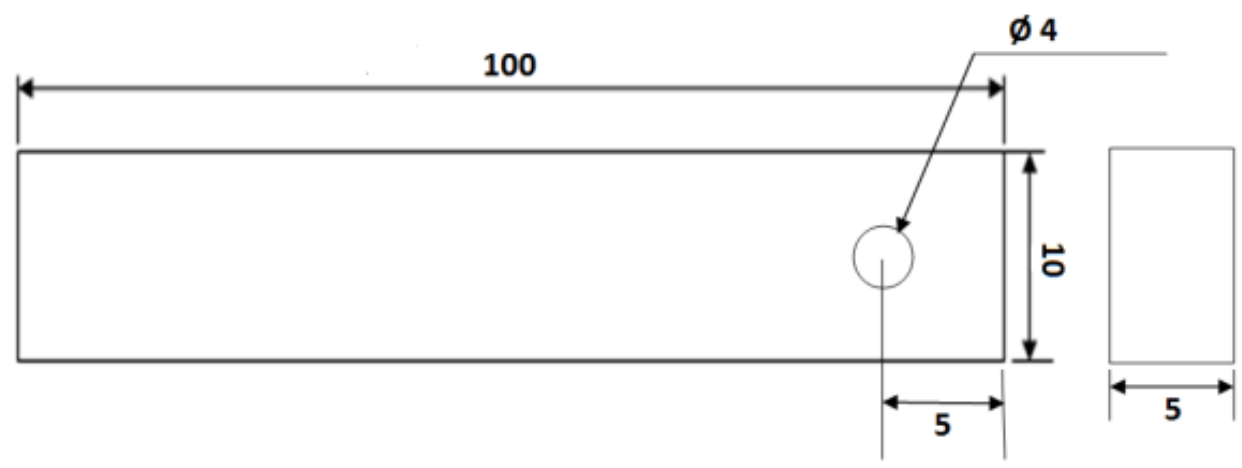

Note: All dimensions in $\mathrm{mm}$

Figure 9. Fatigue test specimen

\section{Result and Discusion}

In the present research, Aluminum reinforced by carbon and glass fibers bonded with using the blend of graphite-polyester matrix. The results presented and discussed as follows:

The tensile strength of FMLs for two specimens can be showed in figure 10. The tensile strength has varied 243 to $258 \mathrm{MPa}$. These results have varied due to different the fabrication of CAGRALLs. The figure indicates that tensile load carry capacity increased up to certain extend and after that, there is a sudden fall at load later. Rajkumar et al [17], used four sheets from aluminum reinforced by four carbon and two glass fibers bonded with epoxy and obtained that tensile strength $(200 \mathrm{MPa})$ is lower to CAGRALLs because of increasing in layers in FMLs led to decrease the tensile strength

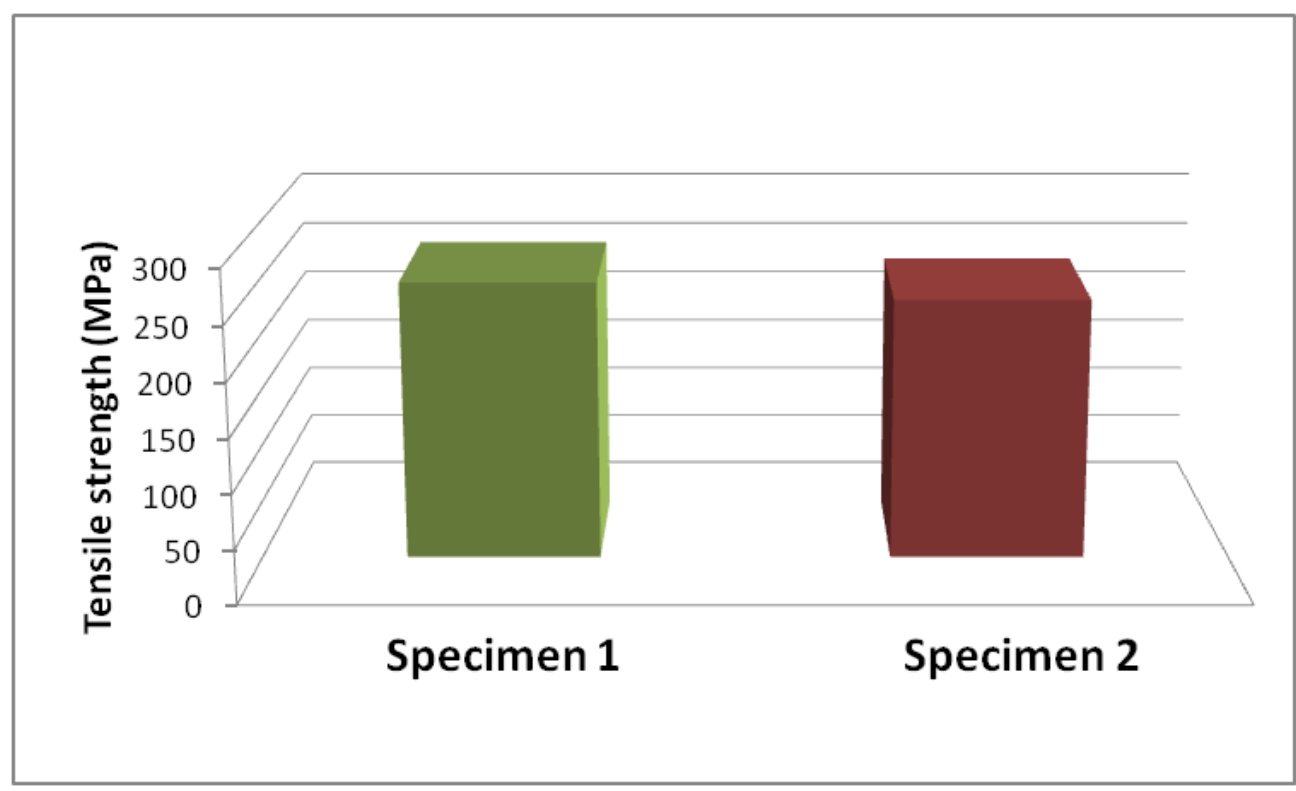

Figure 10. Tensile strength values for CAGRALLs

Figure 11 shows the elastic modulus values of CAGRALLs for two specimens. The figures is indicated the variation from 2.5 to $3.0 \mathrm{GPa}$. Harichandan et al [19], used eight layers from aluminum reinforced by carbon and jute fiber bonded and obtained that elastic modulus $(2.37 \mathrm{GPa})$ is lower to CAGRALLs because of increasing in layers led to decrease the elastic modulus and using carbon with jute fibers led to have the low elastic modulus by comparing with using carbon and glass fibers. 


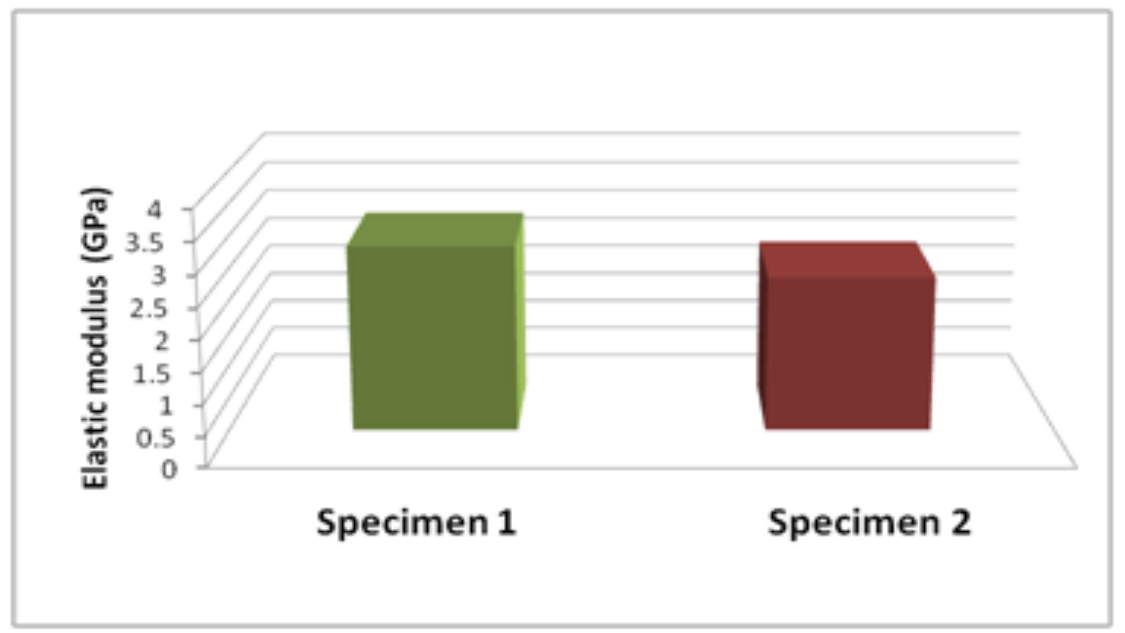

Figure 11. Elastic modulus values for CAGRALLs

Figure 12 shows the yield strength values of CAGRALLs for two specimens. The figure is indicated that the variation is very small from 189 to $213 \mathrm{MPa}$. Harichandan et al [19], obtained that yield strength (35 MPa) is lower to FMLs because it is reduced with increasing layers. Aluminum alloy 2024-T3 has the ratio of ultimate to yield strength 1.5. The CAGRALLs in this study have the ratio of ultimate to yield strength that varied from 1.14 to 1 . 4 . We note that the ratio is near.

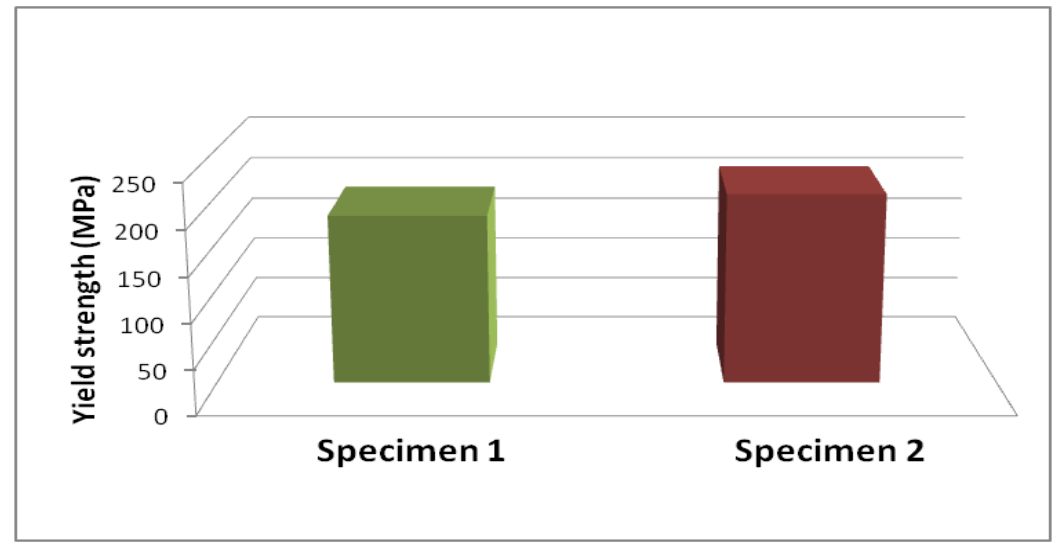

Figure 12. Yield strength values for CAGRALLs

Figure 13 shows elongation at fracture values of CAGRALLs for two specimens. The figures is indicated the variation from 9 to $12.5 \%$. The variation of results is done due to different fabrication and it is within limit.
Rajkumar et al [17], obtained that elongation at fracture $(8.5 \%)$ is lower than CAGRALLs. We note that CAGRALLs with using blend of epoxy-novolac have higher by comparing with using epoxy in FMLs.

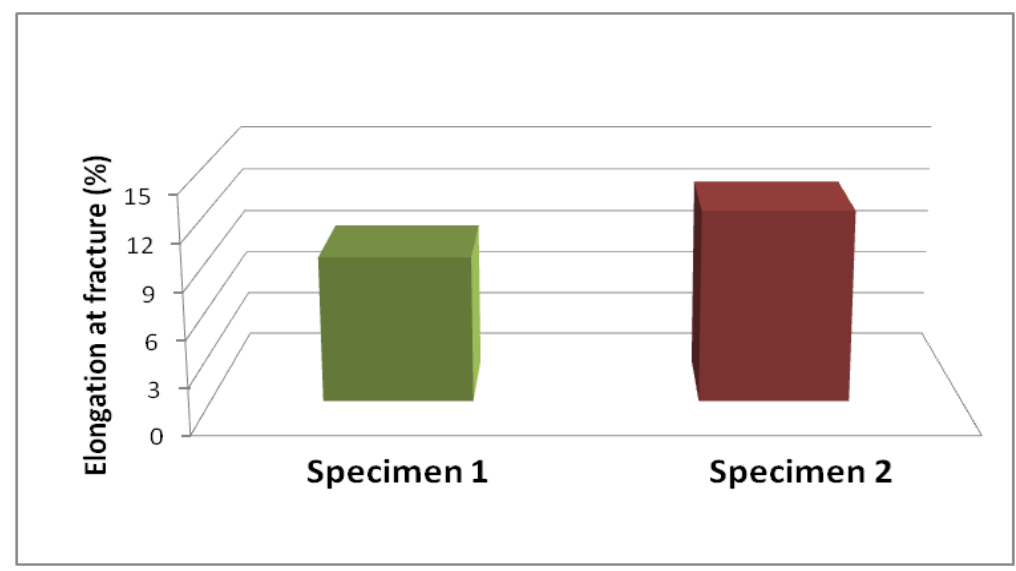

Figure 13. Elongation at fracture values for CAGRALLs 
Figure 14 shows the flexural strength for CAGRALLs. The figure indicates that the flexural strength varied from 359 to $398.67 \mathrm{MPa}$. The variation of these results has obtained respect to different fabrication of theses specimens. However, the variation is within limit. Rajkumar et al [17], obtained the flexural strength $(320 \mathrm{MPa})$ is within limit than CAGRALLs because of increasing in layers led to increase the flexural strength. It indicates that graphitepolyester adhesion is better than epoxy for CAGRALL.

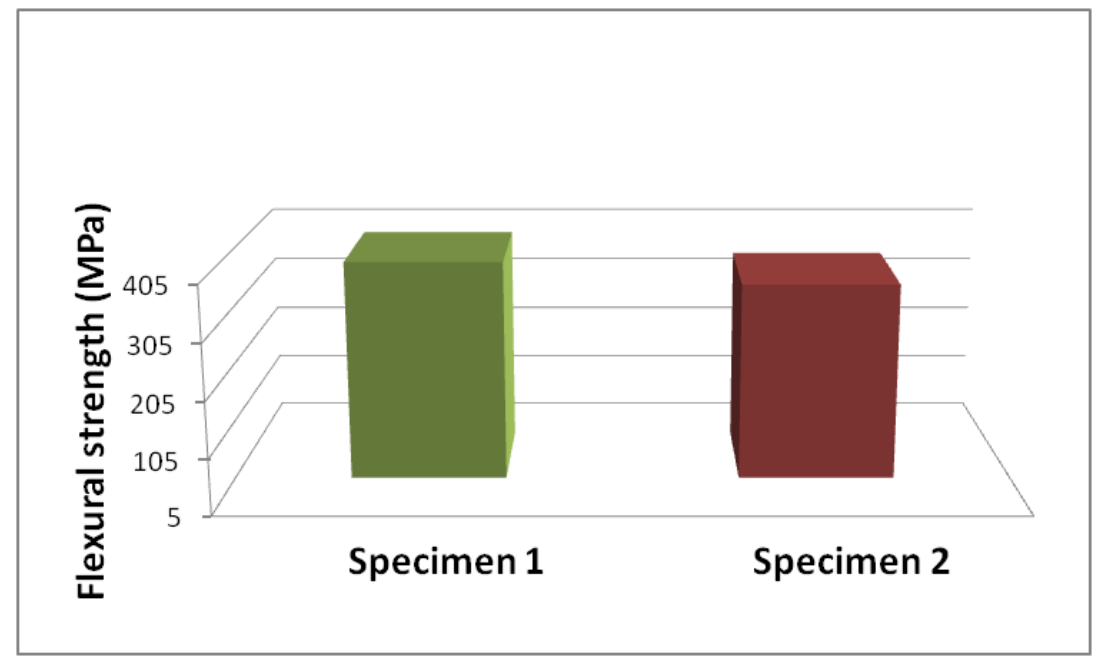

Figure 14. Flexural trength values for FMLs

Figure 15 shows the flexural modulus for CAGRALLs. The figure indicates that the flexural strength is varied with two specimens. The variation of these results has obtained respect to different fabrication of specimens. However, the variation is within limit. The figure indicates the variation from 1.66 to $1.71 \mathrm{GPa}$ for flexural modulus. Hassan et al [18], obtained the flexural modulus $(0.7 \mathrm{GPa})$ is lower than CAGRALLs in this study because of increasing in layers led to decrease the flexural modulus.

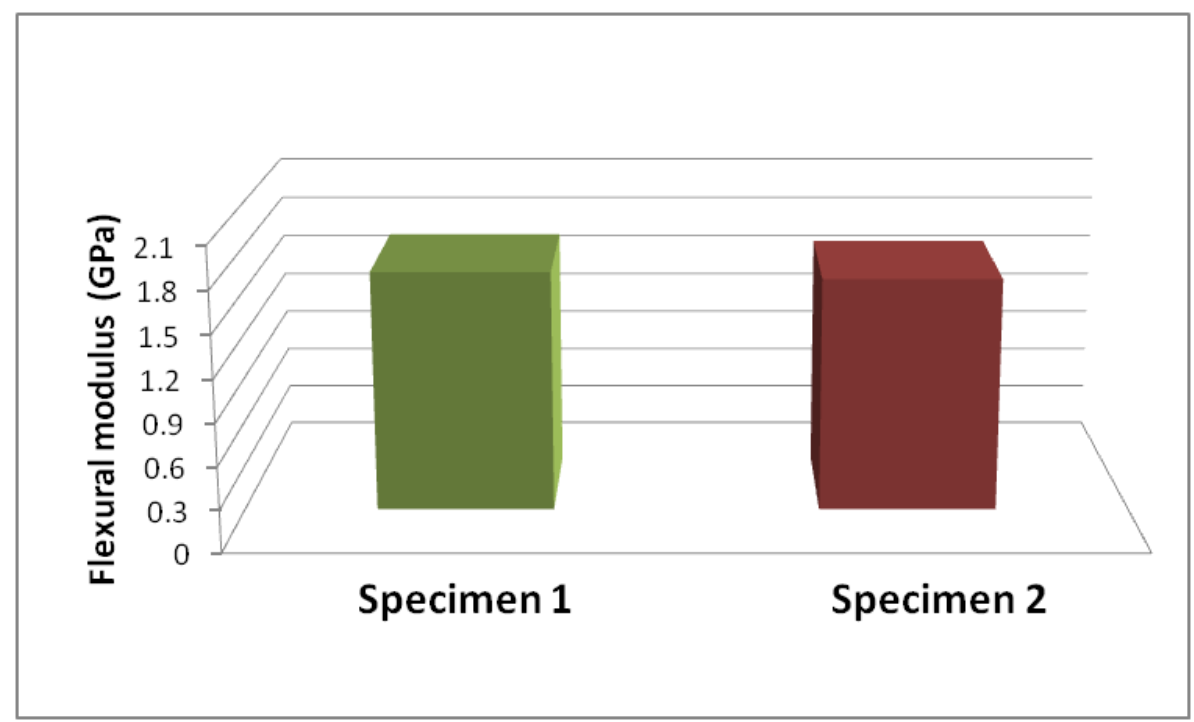

Figure 15. Flexural modulus values for CAGRALLs

The flexural test is applied to the combined stresses: the pressure stress is in the outer surface and the shear stress occurred in inner surface [26]. Figure 16 shows the shear strength for CAGRALLs. The figure indicates that the shear strength is varied for three specimens. The figure is indicated that the shear strength is varied from 25.5 to 28.24 MPa. It has varied with respect different specimens. 


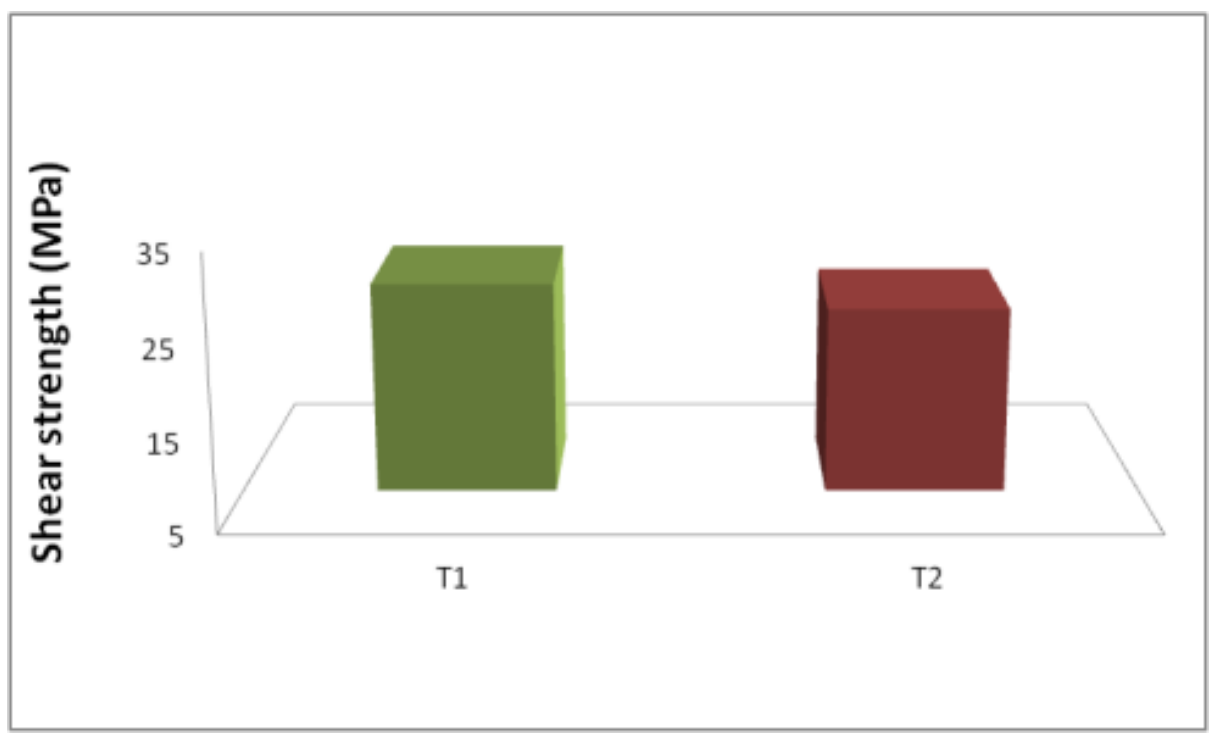

Figure 16. Shear strength values for FMLs

Figure 17 shows the impact toughness for two CAGRALLs. The figure indicated that the impact toughness is varied from 28.55 to $29.2410^{-4} \mathrm{~J} / \mathrm{mm}^{3}$. The figure indicated that the impact energy observations for different samples are almost same. The variation is minimal. Vasumathi et al [15], obtained the impact toughness $\left(23.2410^{-4} \mathrm{~J} / \mathrm{mm}^{3}\right)$ is lower than CAGRALLs in this study because of using carbon with jute fibers led to have the low impact toughness by comparing with using carbon with glass fibers.

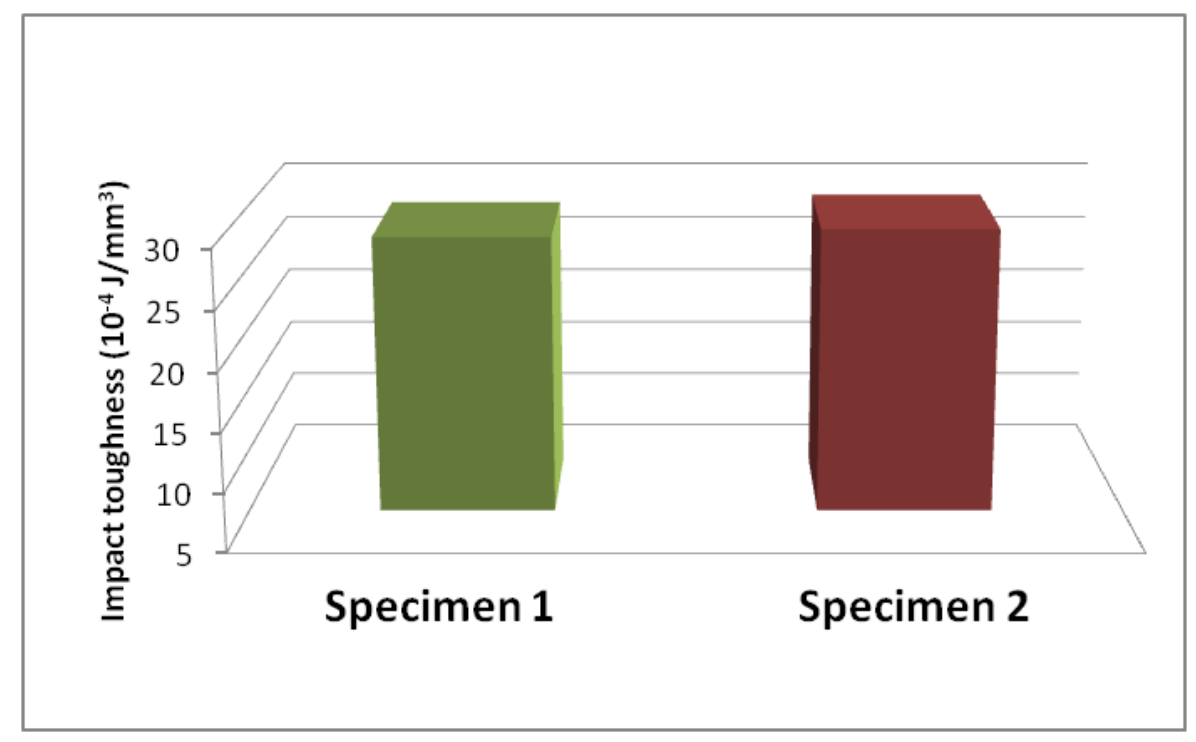

Figure 17. Impact toughness values for FMLs

In this work, we have used applied reversed stresses $(\mathrm{R}=\mathrm{-}$ 1). Figure 18 has explained the number of life under cyclic loadings. At reversed stress $(100 \mathrm{MPa})$, the number of life for FMLs is $\left(2.104 \times 10^{4}\right.$ cycles). At reversed stress (200 $\mathrm{MPa})$, the number of life for FMLs is (5.234 x $10^{3}$ cycles). Chulpova et al [14], used The GLARE 3/2 lay-up has unidirectional fiber. The range of stress $(R=0.04)$ was used. The GLARE has high number of cycles with using epoxy by comparing with FMLs with using blend of graphite-polyester because this blend has more voids that led to reduce number of cycles. Qaiser et al [16], used aluminum sheet reinforced by Kevlar 49 fiber cloth bonded by epoxy with range of stress $(\mathrm{R}=5)$ and obtained that the number of cycles ( 3000 cycles) is lower to CAGRALLs because of carbon fiber have excellent fatigue resistance by comparing with other fibers. The Kevlar fiber was considered hinder for any crack propagation. Typically, the range of stresses is lower than zero $(\mathrm{R}<0)$ caused low fatigue life for composite materials [27]. 


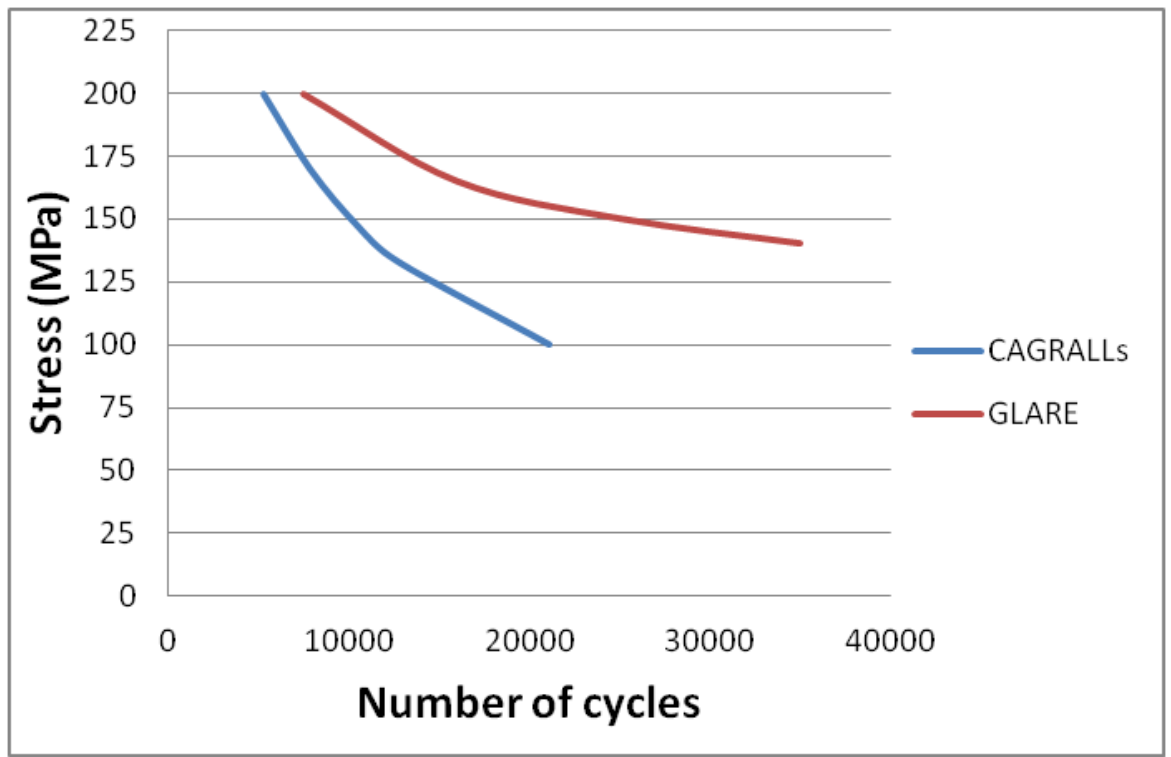

Figure 18. S-N curve for FMLs

The design of wing must be caused decreasing in its weight sothat aluminum used more than metals like steel. The dnsity of aluminum is $2.78 \mathrm{~g} / \mathrm{cm}^{3}$ and steel is $7.86 \mathrm{~g} / \mathrm{cm}^{3}$ [25]. Steel has good mechanical properties but is high density that causd to increase fuel consumption. The density has achieved from fabrication of FMLs $(2.0543$ $\mathrm{g} / \mathrm{cm}^{3}$ ). These FMLs has caused reduction $26.1 \%$ of aircraft wing weight by comparing with aluminum alloys 2024-T3, which has used in manufacturing in this part.

\section{Conclusion}

This study was the first attempt to know and study the changes and improvement of mechanical properties for CAGRALLs, which used in manufacturing of aircraft wing. The purpose of using composite materials is gived the good mechanial properties as wellas lower weight. This study is led to improve in the mechanical properties of aircraft wing such as tensile, flexural, shear, impact and fatigue and to decreae the wieght. It is led to reduce in the weight of aircraft wing by using FMLs over aluminum alloy 2024-T3.

\section{Acknowledgment:}

This work was supported by Diayala University, college of Engineering and Mechanial Engineering Department, which is gratefully acknowledged.

\section{References:}

[1] Johnson, A. F., Kempe, G., and Simon, J. "Design of composite wing access cover under impact loads." Applied Composite Materials (2000): 219-229.

[2] Matthews, F. L., Davies, G. A. O., Hitchings, D., and Soutis, C. Finite element modelling of composite materials and structures. Abington Cambridge CB1 6AH, England: Woodhead Publishing Limited, Abington Hall, 2000.
[3] Dou, X., Malingam, S. D., Nam, J., and Kalyanasundaram, S. "Finite Element Modeling of Stamp Forming Process on Fiber Metal Laminates." World Journal of Engineering and Technology ( 2015 ): 247.

[4] Sathyaseelan P., Logesh K., Venkatasudhahar M., and Dilip Raja N. " Experimental and Finite Element Analysis of Fibre Metal Laminates (FML'S) Subjected to Tensile, Flexural and Impact Loadings with Different Stacking Sequence." International Journal of mechanical \& mechatroncs Engineering (2015).

[5] Hombergsmeier, E. . "Development of advanced laminates for aircraft structures." In Proceedings of 25th International Congress of the Aeronautical Sciences. 2006, September. pp. 3-8.

[6] Tutle, M E. Structural analysis of polymeric. New York, , U.S.A: Marcel Dekker, Inc, 2004.

[7] Saleh, H E. M. Polyester. Cairo, Egypt: Published by InTech Design Team, 2012 September.

[8] Dholakiya B. Z., and Patel K. D. "Synthesis, characterization and glass reinforced composites of low styrene emission unsaturated polyester resin having improved fire resistance and mechanical properties." MMAIJ (2007).

[9] Sanchez, E. M. S., Zavaglia, C. A. C., and Felisberti, M. I. "Unsaturated polyester resins: influence of the styrene concentration on the miscibility and mechanical properties. Polymer." Elsevier Science (2000): 765-769.

[10] Kulkarni, P. " Evaluation of Mechanical Properties of AL 2024 Based Hybrid Metal Composites." IOSR Journal of Mechanical and Civil Engineering (IOSR JMCE) (2015): 2278-1684.

[11] Davis, J R. "Aluminum and Aluminum Alloys." ASM International (2001): 351-416. 
[12] Haji, Zyad Nawaf. "Low cycle fatigue behavior of aluminum alloys AA2024-T6 and AA7020-T6." Diyala Journal of Engineering Sciences First (2010): 127-137.

[13] Hamed, Mohammed Ismael. "Free Vibration Analysis Of Composite Aircraft Wing With Circular Cutout Using Finite Element Method." DIYALA JOURNAL OF ENGINEERING SCIENCES 8.4 (2015): 740-752.

[14] Chlupová, A., and Kozák, V. FATIGUE CRACK GROWTH AND DELAMINATION IN FIBER METAL LAMINATE (GLARE) DURING LOADING WITH POSITIVE MEAN STRESS. 18thInternational Conference ENGINEERING MECHANICS, 300, (2012). pp. 531-536.

[15] Vasumathi, M., and Murali, V. Effect of alternate metals for use in natural fibre reinforced fibre metal laminates under bending, impact and axial loadings. International Conference On DESIGN AND MANUFACTURING. Procedia Engineering, 64, (2013). 562-570

[16] Qaiser, M. H., Umar, S., and Nauman, S. Development and characterization of fatigue resistant Aramid reinforced aluminium laminates (ARALL) for fatigue Critical aircraft components. In IOP Conference Series: Materials Science and Engineering (2014). (Vol. 60, No. 1, p. 012050). IOP Publishing.

[17] Rajkumar, G. R., Krishna, M., Narasimhamurthy, H. N., Keshavamurthy, Y. C., and Nataraj, J. R. Investigation of tensile and bending behavior of aluminum based hybrid fiber metal laminates. International Conference on Advances in Manufacturing and Materials Engineering (AMME ). Procedia Materials Science, (2014). 5, 60-68.

[18] Hassan, M. K., Abdellah, M. Y., Azabi, S. K., and Marzouk, W. Investigation of the Mechanical Behavior of Novel Fiber Metal Laminates. International Journal of Mechanical (2015).

[19] Harichandan, A., and Kumar, K. R. V. Study on tensile behaviour of carbon jute aluminium-fibre metal laminates. International journal of mechanical and production engineering, (2016). ISSN, 2320-2092.

[20] Emberey, C. L., Milton, N. R., Berends, J. P. T. J., Van Tooren, M. J. L., Van der Elst, S. W. G., \& Vermeulen, B. Application of knowledge engineering methodologies to support engineering design application development in aerospace. In 7th AIAA ATIO Conf, 2nd CEIAT Int'l Conf on Innov and Integr in Aero Sciences, 17th LTA Systems Tech Conf; followed by 2nd TEOS Forum (2007). (p. 7708).

[21] Said, L., Said, D., \& Ali, B. Effect of adding graphite powder to a UP polymer on friction and wear for different loads and rubbing speeds, Key Engineering Materials (2014). Vols. 592-593, pp 668-671.

[22] POLYESTER RESIN ES 1060 ROZACHIM AD , 5100 G. Oryahovitsa, (2015), www.rozachim.eu.
[23] Astrom, B. Manufacturing of Polymer Composites (1997). (pp. 1-175). Chapman \& Hall.

[24] Al-Mutairee, H. M., \& Al-Hamdani, H. A. Flexure Behavior of Hybrid Continuous Deep Beam Strengthened by Carbon Fiber Reinforced Polymer. Journal of University of Babylon, (2017). 25(5), 1580-1592.

[25] American Society for Metals. Metals handbook. 2. Properties and selection: nonferrous alloys and specialpurpose materials. American Society for Metals. (1990).

[26] Rijab M. A., Kader E. I., Hamod A. A.,and Hameed A. H. I., Mechanical properties of silica, graphite and carbon fiber reinforced composites, International Journal of Engineering and Technology (IJET), (2017), 9 (5) 2319-8613.

[27] Tomblin, J., and Seneviratne, W. Determining the fatigue life of composite aircraft structures using life and load-enhancement factors. Final report, Air Traffic Organization, Washington DC, USA. (2011). 